Научная статья

УДК 29:004.9:316.7

DOI: 10.18101/1994-0866-2021-4-18-25

\title{
ТРАНСФОРМАЦИЯ РЕЛИГИИ В УСЛОВИЯХ ЦИФРОВОГО ОБЩЕСТВА
}

\author{
(C) Чеснова Елена Николаевна \\ кандидат философских наук, \\ доцент кафедры философии и культурологии, \\ Тульский государственный педагогический университет им. Л. Н. Толстого \\ Россия, 300026, г. Тула, проспект Ленина, 125 \\ elenika.nova@yahoo.com
}

\begin{abstract}
Аннотация. В статье раскрывается специфика современного состояния религии и религиозных феноменов на основе идеи «обнуления», «цифровизации» религии, предложенной в исследовании М. Ю. Смирнова, рассматривается трансформация религии. Процесс «цифровизации религии», «обнуления» закономерен, носит характер адаптации религии к современным условиям развития общества и культуры, а также стремление сохранить влияние в обществе. Используя цифровые продукты и технологии, вступая в интернет-пространство, религия стремиться открыть доступ к религиозному наследию, культуре, традиции, быть понятной и доступной большему числу людей. Адаптацию религии, ее трансформацию, можно проследить в различных направлениях деятельности по внедрению, освоению IT-сферы, интернет-пространства, цифрового пространства. В рамках обоснования трансформации религии даются примеры цифровизации религии, религиозных цифровых продуктов.

Ключевые слова: цифровая сфера, цифровизация религии, обнуленное поле религии, трансформация религии, адаптация религии, онлайн-религия, религия онлайн, религиозный феномен, вера, квазирелигия, киберрелигия, квазирелигиозные феномены, интернет-пространство, информационно-коммуникационные технологии.
\end{abstract}

\section{Для цитирования}

Чеснова Е. Н. Трансформация религии в условиях цифрового общества // Вестник Бурятского государственного университета. Философия. 2021. Вып. 4. С. 18-25.

Религия и вера — важные феномены духовно-нравственной жизни человека. В современных условиях они подвергаются процессам трансформации, как и все сферы жизни и деятельности человека, а именно цифровизации. Для 90-х гг. XX в., первого десятилетия XXI в. характерна трансформация под знаком «квази». Можно было наблюдать такие феномены, как квазирелигия, квазивера, квазирелигиозность. Хотя на рубеже XX-XXI вв. уже вводится различие терминов «онлайн-религия» и «религия онлайн» (Кристофер Хэлланд) [5], активно внедряется термин «онлайн-религия» (Хейди Кемпбелл), сначала в западной социологии, потом в отечественной используются термины «религиозный рынок» и «рынок религий» [5]. В дальнейшем мы постепенно отходим от употребления термина с приставкой «квази». В начале второго десятилетия XXI в. совершается переход к термину «киберрелигия» (А. П. Забияко, Д. А. Пратынина, К. А. Колкунова и др.) и сопутствующим ему терминам «религия геймеров» (А. П. Забияко), «киберпространство как новый образ шаманизма» (Е. А. Воронкова) и начинаем говорить о таких явлениях, как «интернет-пространство религии» [3] 
(Г. А. Буваева), «цифровая религия» (Г. А. Буваева), «цифровизация религии» (Г. А. Буваева), «обнуление религии» (М. Ю. Смирнов), «цифровое православие» [11] (Е. А. Островская), «виртуальная умма» [7] (А. Игнатович), «цифровая идентичность» [9] (А. В. Конева), «рынок религий» как часть «Глобального рынка информации» [5] (И. С. Журинский, О. Ф. Лобазова) и т. д. По своей сути это есть трансформация квазирелигиозных феноменов по отношению к традиционным формам. Квазирелигия, квазивера, квазирелигиозность - новые формы религиозных феноменов, которые связаны с ними, являются ступенью их развития, трансформации с учетом складывающихся условий в обществе, культуре, экономике, науке и т. п. Но в феномене «квази» религиозное начало подчинено светскому, начинают преобладать «нерелигиозные компоненты - например, этнические, политические, социальные, экологические, сциентические, этические, психологические и другие» [6, с. 191]. Ряд исследователей как, например, М. Ю. Смирнов полностью разграничивает квазирелигии (рассматривая их наравне со светскими идеологиями) и «обнуление религии», религию в сфере современных информационных технологий (с ее режимами «религии онлайн» и «онлайн-религии»). М. Ю. Смирнов считает последние традиционными религиями, но изменившимися в условиях социальной практики, утратившими прежнюю функциональность, пересмотревшими базовые компоненты религиозного комплекса, устои религиозной институциональности, и не растратившими «потенциал духовных, нравственных и социальных возможностей» [12].

В статье мы придерживаемся идеи «обнуления» религии, как ее вводит и обосновывает М. Ю. Смирнов. Исследователь раскрывает смысл «обнуления» через переложение смысла популярного сейчас в научной среде термина «цифровизация». М. Ю. Смирнов опирается на «этимологию слова "цифра"», которое в арабском языке понимается как «пустой, или нуль» [12]. В своем исследовании автор обосновывает, что использование цифр, их сакральных, мистических значений сопровождает историю человечества, приводит примеры такой «цифровизации» в «древнейшей вульварной и фаллической символике» [12], пифагореизме, христианстве, каббалистических поисках. М. Ю. Смирнов дает определение цифровизации в ее широком значении и определяет ее как «перенос в цифровую среду функций и видов деятельности, ранее непосредственно выполнявшихся людьми и организациями» [12], что приводит к возникновению новых социальных, коммуникативных практик, отношений, созданию «цифровых продуктов» (услуг), искусственного мира («в диапазоне от дополнительной до виртуальной реальности» [12]), который действует в реальном времени. Все это приводит, по мысли М. Ю. Смирнова, к «эффекту обнуления». Суть данного эффекта «сброс прежних, устоявшихся моделей общения и издавна сложившихся форм коммуникации» [12], меняется формат существования человека в сочиальном пространстве [12]. Институты трансформируются, получают и реализуют новые функции. Данный процесс не всегда является подготовленным, заведомо ожидаемым для самих институтов, но неизбежным. Данный процесс «обнуления», «цифровизации» религии мы понимаем как процесс трансформации, адаптации религии, религиозных феноменов, который находит свое практическое выражение в новых формах и пространстве коммуникации, услугах, в самой культуре («обнуление» затрагивает всю культуру) и т. д. Этому и посвящена наша ста- 
тья - показать закономерность процесса трансформации религии в условиях «цифровизации», «обнуления», адаптации религии к новым вызовам времени, показать, как именно на практике происходит трансформация религии в условиях цифрового общества, то есть представить сферы внедрения освоения религией IT-сферы, интернет-пространства и соответствующие им примеры реально существующих «цифровых продуктов», новых форм, видов коммуникации.

В исследовании использованы следующие методы: описание, анализ современного состояния религии, освоения религией IT-сферы, интернет-пространства, классификация цифровых продуктов и освоенных религией цифровых технологий на примере христианства (католицизм, протестантизм, православие), ислама, буддизма, иудаизма, новых религиозных движений и культов и т. д.

А. А. Коноплева отмечает, что культурное «обнуление» соответствует вызовам современной эпохи, несет как позитивные, так и негативные последствия [10]. Религия, религиозные феномены принадлежат культуре, связаны с ней. На современном этапе «под влиянием секуляризационных процессов, распространения массовой культуры, глобализации» они становятся «универсальными мировоззренческими элементами» [13], реализуются в мирской реальности. Поэтому включение религии, ее религиозных феноменов в процесс «цифровизации», «обнуления» закономерно. В этом мире общение человека с другими людьми происходит через интерфейс, дистанционно, что не требует личного присутствия, включенности и приводит к обеднению эмоциональных состояний, которые может испытать человек при личной включенности в процесс. Процесс трансформации религии под воздействием информационно-коммуникативных технологий, цифровизации закономерен. Многие виды деятельности человека перешли в сферу виртуальных практик. Как пишет М. Ю. Смирнов: «Все мы ежедневно включены в виртуальные практики - от общения в социальных сетях до оплаты покупок и услуг в электронной форме» [12]. Религия в интернет-пространстве при внедрении в свою практику современных информационных технологий переходит с устоявшихся традиционных моделей общения, форм коммуникации на модели общения «онлайн», что неминуемо приводит к зарождению нового, «обнуленного» поля религии, соответствующего современному публичному формату общения и жизни человека в социальном пространстве [12], интернетпространстве. Цифровые институты, цифровые продукты (услуги, информационные ресурсы, электронные сервисы), виртуальное пространство, дополненная реальность создают мир с духовным измерением и человеческой культурой. Религии, будь то мировые, национальные или новые религиозные движения и культы, активно включаются в IT-сферу, процесс освоения интернетпространства, цифровизации. Христианство (католицизм, протестантизм, православие), например, органично соответствует «процессам и тенденциям информационного общества» [12]. Буддизм (Г. А. Буваева), ислам (А. Игнатович), иудаизм также участвуют в процессе «цифровизации». Среди новых религиозных движений и культов активно используют интернет-пространство, информационно-коммуникационные технологии (ИКТ) представители организаций, которые признаны экстремистскими. Например, последователи Свидетелей Иегова используют видео-конференц-связь для проведения своих религиозных собраний, обсуждений проблем общины, проповеди в рамках богослужений, миссионер- 
ской практики. Сферы внедрения освоения религией IT-сферы, интернетпространства:

1) социальные сети и месседжеры, например, папы римские начиная с Бенедикта XVI имеют «собственный аккаунт в социальной сети Twitter» ${ }^{1}$. Имеются также разработанные персонально для христиан социальные сети. Например, Faithbook является социальной сетью, которая была разработана христианской организацией «для знакомства и координации христиан»²);

2) поисковые системы в интернете, например, в цифровом пространстве уже действуют поисковые системы, разработанные для верующих и помогающие в автоматическом режиме находить информацию, ресурсы, которые не являются греховными, не приводят к соблазнам. Для мусульман отечественными разработчиками была создана и несколько лет действовала поисковая система «I’m Halal», в рамках иудейского сообщества была разработана поисковая система «Koogle» ${ }^{3}$. Уже в самих названиях данных цифровых продуктов содержится отсыл к важным религиозным установлениям данных религиозных традиций. В исламе «халяль» («халал») - разрешенное, в иудаизме «кошерное», т. е. пригодное, правильное;

3) интернет-сервис (веб-сервис, иифровой продукт) по реализации религиозных нужд, например, «Tweet Your Prayers» на платформе Twitter. Данная программа помогает верующим, не имеющим возможность самим посетить знаменитую Стену Плача в Иерусалиме и оставить в ней свою молитвенную записку, послать ее через интернет ${ }^{4}$, составляют виртуальные туры по священным местам, наиболее востребованными являются «Виртуальный тур по Храму Гроба Господня» ${ }^{5}$, виртуальный тур в Мекку (проект «Miraj»), призванный подготовить паломника к хаджу или умре. Также можно говорить и об электронных библиотеках, которые содержат в открытом доступе религиозную литературу. Например, каталог православных ресурсов «Православное христианство.ru» содержит электронные коллекции по православию и др.;

4) сайты знакомств для людей, позищионирующих себя по религиозному, конфессиональному признаку (сайты религиозных знакомств). Например, среди людей, причисляющих себя к православию, православных верующих популярными являются следующие сайты: «Азбука верности» ${ }^{6}$, «Православный сайт знакомств» ${ }^{7}$, «Православные знакомства онлайн» ${ }^{1}$, «Православные знакомства ${ }^{\mathrm{TM}_{\rangle}{ }^{2}}$

\footnotetext{
${ }^{1}$ Цифровая религия. Проникновение церкви в онлайн // Novate.Ru [сайт]. Раздел: Гаджеты. Дата публикации: 19.03.2013 г. URL: https://novate.ru/blogs/190313/22688/ (дата обращения: 14.08.2021). Текст: электронный.

2 Там же.

3 Там же.

${ }^{4}$ Там же.

${ }^{5}$ Виртуальный тур по Храму Гроба Господня // @ santosepulcro.co.il 2016-2020 [сайт] URL: https://santosepulcro.co.il/tours/santosepulcro/ru/html5/index.html (дата обращения: 01.04.2021). Текст: электронный.

${ }^{6}$ Азбука верности // Православная служба знакомств «Азбука Верности» [сайт]. URL: https://azbyka.ru/znakomstva/ (дата обращения: 01.04.2021). Текст: электронный.

${ }^{7}$ Православный сайт знакомств // URL: https://xn--80ab5bj.xn--p1ai/ (дата обращения: 14.08.2021). Текст: электронный.
} 
(группа создана на платформе социальной сети «ВКонтакте»), «Молодежный проект "Давай повенчаемся"» ${ }^{3}$ (группа создана на платформе социальной сети «ВКонтакте») и т. д. Существуют сайты, которые предоставляют информацию и ссылки на сайты, форумы, странички религиозных знакомств и создания семьи. Каталог православных ресурсов «Православное христианство.ru» ${ }^{4}$, например, содержит 18 таких ссылок на ресурсы, с кратким описанием их направлений деятельности;

5) персональные POS-терминаль в храмах для сбора пожертвований. За рубежом многие прихожане не носят с собой наличные деньги, расплачиваясь при помощи чипа, вживленного в руку, палец, пластиковой карты, поэтому для сбора пожертвований в общую «корзину» используют оплату по безналичному расчету и специальные встроенные в церковную скамью терминалы.

6) VR-ųерковь, онлайн-службы (примером VR-цееркви можно считать виртуальную церковь, созданную в 2016 г. на бесплатной платформе в социальной сети AltSpaceVR американским пастором Ди-джей Сото для проведения виртуальных богослужений и проповедей. Данный вариант освоения виртуального пространства для проведения богослужения не первый в своем роде. Еще десятилетием ранее «в 2006 году, когда открылась бесплатная регистрация на одной из первых виртуальных платформ Second Life, там появились церкви, храмы, синагоги и мечети, где проводились богослужения и медитации» [4]. Но постепенно данные начинания пошли на убыль. Проект пастора Сото работает, в рамках данного проекта он общается не только со своими прихожанами-верующими, но и с атеистами, которые также посещают его виртуальные богослужения и задают интересующие их вопросы. Онлайн-службы могут быть реализованы в рамках работы сайта, примером может выступать сайт «Храм ТВ» (Телевизија Храм. Српска Православна Црква);

7) VR-священник (ведение блога в социальной сети священнослужителем);

8) робот-священник, например, в 2017 г. представителями одного из направлений протестантизма (евангельские христиане) был разработан роботсвященник BlessU-2 и поставлен в Евангелической церкви города Виттенберга (Германия, земля Саксония-Анхальт), по заказу которой велась разработка робо$\mathrm{Ta}^{5}$. Это знаковое событие, так как город Виттенберг связан с именем Мартина

1 Православные знакомства онлайн // URL: https:/www.edarling.ru/ sovetchik/znakomstvo/pravoslavnye-znakomstva (дата обращения: 14.08.2021). Текст: электронный.

2 Православные знакомства // ВКонтакте [социальная сеть]. URL: https://vk.com/pravlove (дата обращения: 14.08.2021). Текст: электронный.

${ }^{3}$ Молодежный проект «Давай повенчаемся»// ВКонтакте [социальная сеть]. URL: https://vk.com/davay_povenchaemsya (дата обращения: 14.08.2021). Текст: электронный.

${ }^{4}$ Православное христианство.ru. Каталог православных ресурсов // (C) 2001-2021, Православное христианство. URL: http://www.hristianstvo.ru/life/family/marriage/ (дата обращения: 01.04.2021). Текст: электронный.

${ }^{5}$ Первый в мире робот-священник появился в «столице Реформации» // РИА Новости. Раздел Религия. Дата публикации: 12:48 30.05.2017 (обновлено: 13:58 15.03.2021). URL: https://ria.ru/20170530/1495376943.html (дата обращения: 14.08.2021). Текст: электронный. 
Лютера и его знаменитыми тезисами, которые дали толчок к основанию лютеранства, протестантского движения. В 2019 г. появился более усовершенствованный человекоподобный вариант буддийского священника по имени Миндар (разработка компании A-Lab Co), данный робот был разработан, чтобы быть официальным проповедником в храме Кодайджи в Киото, Япония;

9) SMS-сервисы и электронные почты (молитва по SMS-сообщению; рассылка важной информации для прихожан посредством SMS или электронным письмом);

10) видео-конференц-связь (BKC). Использование религиозными организациями различных систем ВКС для проведения богослужений-онлайн, миссионерских практик, встреч с паствой онлайн, которые носят закрытый характер, только для представителей общины верующих используется организацией, если ее члены находятся в разных областях, регионах страны, для объединения малочисленных групп верующих, у которых нет возможности иметь своего священника и приход, место богослужения (церкви, молитвенного дома, синагоги, мечети и т. п.).

Перечень и более детальная классификация могут быть продолжены, можно больше уделить внимание созданию виртуальных туров по религиозным местам, подробно рассмотреть внедрение цифровых технологий и их продвижение в религиозном туризме, паломничестве.

В рамках статьи мы показали направления, виды цифровых продуктов, виды деятельности IT-сферы, интернет-пространства, цифровой сферы, которые осваиваются религией, верующими, людьми, ассоциирующими себя с той или иной религиозной традицией, интересующимися вопросами веры и религии. Как отмечает М. Ю. Смирнов: «Любая религия всегда и везде существует только так, как её понимают, мыслят, переживают конкретные люди здесь и сейчас» [12]. Поэтому «обнуление» религии ведет к ее адаптации к запросам и ритму жизни современных верующих, современного плюралистично настроенного общества, где человек, интересующийся вопросами веры, религии, ищет ответы в интернете, а не в личной беседе со священнослужителем в храме, не через обучение основам религиозных культур (данный предмет, как и дисциплина «Религиоведение» был в школах и высших образовательных учреждениях не всегда и не везде сейчас входит в учебный план), не через воскресные школы. Данный поиск подчас носит стихийный характер, человек, не имея объективной, достоверной базы знаний о религии, может попасть в организации, которые могут нанести вред жизни и душевному здоровью человека, так как он, не имея знаний, может попасть под их влияние, влияние их лидера. Адаптация, цифровая трансформация религии несет в себе и духовную миссию по защите самой религии и людей. Осваивая цифровые технологии, интернет-пространство, религия стремиться предоставить людям доступ к своему богатейшему религиозному, культурному, историческому опыту, быть близкой и понятной новым поколениям, объединять вокруг себя. Для сохранения своего влияния (чтобы оставаться «зонтиком над обществом» (Питер Бергер)) религии необходима своевременная модернизация. Потребность в религии, стремление руководствоваться в жизни религиозным вероучением, возможность быстрого доступа к действиям культового характера должны быть реализованы с учетом произошедшей ценностной, куль- 
турной, технологической (цифровизации) трансформации в обществе. Представленные в статье цифровые продукты, сферы внедрения освоения религией IT-сферы, интернет-пространства показывают уже произошедшие перемены. С учетом современных угроз пандемии COVID-19 цифровая трансформация религии будет продолжаться, цифровые продукты будут востребованы большим числом людей.

\section{Лuтература}

1. Башмакова М. Вера с надеждой на любовь. Можно ли найти счастье на сайтах религиозных знакомств // Огонёк. № 4224 октября 2016. C. $26 . \quad$ URL: https://www.kommersant.ru/doc/3119363 (дата обращения: 01.04.2021). Текст: электронный.

2. Борисова Л. В. Проблема соотношения разума и веры в цифровую эпоху // VI Декартовские чтения «Декарт и современные формы трансляции научного знания»: материалы международной научно-практической конференции / под общей редакцией А. И. Пирогова, Т. В. Растимешиной. 2019. С. 118-127. URL: https://www.elibrary.ru/download/elibrary_42377788_42737557.pdf (дата обращения: 01.04.2021). Текст: электронный.

3. Буваева Г. А. Интернет-пространство религии и «цифровизация буддизма» // Вестник Калмыцкого университета. 2020. № 2(46). С. 86-91. URL: https://www.elibrary.ru/download/elibrary_43084561_27973306.pdf (дата обращения: 01.04.2021). Текст: электронный.

4. Елкина В. Американский священник создал церковь в виртуальной реальности // OОО "РБ.РУ" (C) 2012-2021 [сайт]. Дата публикации материалов: 13.03.2018 г. URL: https://rb.ru/story/vr-church/ (дата обращения: 14.08.2021). Текст: электронный.

5. Журинский И. С., Лобазова О. Ф. Религия в эпоху цифровых технологий: некоторые аспекты процесса обновления // Наука России: цели и задачи: сборник научных трудов по материалам XXI Международной научной конференции. Екатеринбург, 2020. C. 87-91. URL: https://www.elibrary.ru/download/elibrary_43088342_90596749.pdf (дата обращения: 01.04.2021). Текст: электронный.

6. Киберрелигия: наука как фактор религиозных трансформаций: монография / А. П. Забияко, Е. А. Воронкова, А. В. Лапин [и др.]; под редакцией А. П. Забияко. Благовещенск: Изд-во Амур. гос. ун-та, 2012. ISBN 978-5-93493-165-1. 208 с. Текст: непосредственный.

7. Игнатович А. Виртуальная умма: определение понятия, его содержание и объем // Thesaurus. зборнік навуковых прац. Заснаваны ў 2015 годзе. Магілёў, 2020. С. 75-82. URL: https://www.elibrary.ru/download/elibrary_43855914_49229104.pdf (дата обращения: 01.04.2021). Текст: электронный.

8. Колкунова К. А. Киберрелигия: наука как фактор религиозных трансформаций // Религиоведческие исследования. 2013. № 7-8. URL: https://cyberleninka.ru/article/n/ kiberreligiya-nauka-kak-faktor-religioznyh-transformatsiy (дата обращения: 14.08.2021). Текст: электронный.

9. Конева А. В. «Цифровая идентичность»: процессы идентификации и репрезентации в сетевой коммуникации // Вестн. Ленингр. гос. ун-та. 2018. № 1. С. 50-60. (дата обращения: 14.08.2021). Текст: непосредственный.

10.Коноплева А. А. Феномен «обнуления» в современной культуре // Манускрипт. 2020. T. 13, № 9. C. 136-139. URL: https://www.elibrary.ru/download/ elibrary_43987579_60610940.pdf (дата обращения: 01.04.2021). Текст: электронный.

11.Островская Е. А. Ритуалы в дискурсах цифрового православия: методология и направления исследования. Концепт: философия, религия, культура. 2020. 4(1). С. 05-120. 
URL: https://concept.mgimo.ru/jour/article/view/359?locale=ru_RU (дата обращения: 14.08.2021). Текст: электронный.

12.Смирнов М. Ю. Цифровизация как «обнуление» религий // Вестник ЛГУ им. А. С. Пушкина. 2019.№ 3. URL: https://cyberleninka.ru/article/n/tsifrovizatsiya-kakobnulenie-religiy (дата обращения: 01.04.2021). Текст: электронный.

13. Чеснова Е. Н., Мартьянова Е. Г. Вера, религиозность и эсхатологические настроения в условиях трансформации мировоззрения и угрозы глобальных проблем современности (на примере COVID-19) // Религиозная идентичность и межкультурные коммуникации: материалы всероссийского научного семинара / ответственный редактор и составление: А. П. Романова, Д. А. Черничкин. Астрахань: Изд-во Астрах. гос. ун-та, 2020. С. 194-202. Текст: непосредственный.

Статья поступила в редакиию 11.10.2021; одобрена после рещензирования 30.10.2021; принята к публикаџии 15.11.2021.

\section{TRANSFORMATION OF RELIGION IN A DIGITAL SOCIETY}

\section{Elena N. Chesnova}

Cand. Sci. (Philos.),

A/Prof. of Philosophy and Cultural Studies Department,

Tolstoy Tula State Pedagogical University

125 Lenina Prospect, Tula 300026, Russia

elenika.nova@yahoo.com

Abstract. The article reveals the specificity of the current state of religion and religious phenomena based on the idea of "a reset", "digitalization" of religion, proposed in M. Yu. Smirnov's study, considers the transformation of religion. The process of "religion digitalization" is expected, it has the character of religion adaptation to the modern conditions of society and culture development. Using digital products and technologies, entering the Internet space, religion strives to open access to religious heritage, culture, traditions, to be clear and accessible to more people. The adaptation of religion, its transformation, can be traced in various areas of activity and development of the IT-sphere, the Internet, and the digital space. When substantiating the transformation of religion, we give the examples of religion digitalization, religious digital products.

Keywords: digital sphere, digitalization of religion, a reset field of religion, transformation of religion, adaptation of religion, online religion, religion online, religious phenomenon, faith, quasi-religion, cyber-religion, quasi-religious phenomena, the Internet space, information and communication technologies, video communication.

\section{For citation}

Chesnova E. N. Transformation of Religion in a Digital Society. Bulletin of Buryat State University. Philosophy. 2021; 4: 18-25

The article was submitted 11.10.2021; approved after reviewing 30.10.2021; accepted for publication 15.11.2021. 